\title{
Related projects according to the European Mountain Pool
}

At the editorial office of eco.mont, we maintain the European Mountain Pool on research in European protected mountain areas.

http://www.alparc.org/our-actions/research-platform/european-mountain-pool

eco.mont - Volume 5, Number 1, June 2013

Related projects in the European Mountain Pool:

Alpine rivers and their ligneous vegetation with Myricaria germanica and riverine landscape diversity in the Eastern Alps: proposing the Isel river system for the Natura 2000 network by Helmut Kudrnovsky

Motorcycling over the Ofenpass: Perception of the Swiss National Park and the Ofenpass from the perspective of motorcyclists by Andrea Jauss \& Norman Backhaus

Lessons learnt from a monitoring endeavour in the UNESCO Biosphere Reserve Entlebuch by Florian Knaus

Sentinel lakes: a network for the study and management of mountain lakes in the French Alps and in Corsica by Birck et al.
Kreiner Daniel: Artenschutzprojekt Deutsche Tamariske (Myricaria germanica). CH-2759

Filli Flurin: Traffic noise at the Ofenpass. CH-4240

Siegrist Dominik: Monitoringkonzept für das UNESCO-Weltnaturerbe Tektonikarena Sardona. $\mathrm{CH}-4376$

Catalan Jordi: Climate history as recorded by ecologically sensitive arctic and alpine lakes in Europe during te last 10000 years; a multi-proxy approach (CHILL 10 000). CH-1604

Jonsson Anders: Impacts of terrestrial input of organic matter into lake ecosystems. CH-3102

Karlsson Jan: Carbon dynamics in lakes. CH-3104

Robinson Christopher Thomas: Long-term biochemical changes of high-mountain lakes in Macun (Swiss National Park). CH-1194

Schanz Ferdinand: Chemical and alogological survey of five high mountain lakes in the SNP. CH-3813 